\title{
Antioxidant and Acetylcholinesterase Inhibition Capacity of Hyrosols From Lamiaceae Plants for Biopesticide Use. The Role of Phenolic Compounds
}

\section{Alexandra GASPAR-PINTILIESCU}

National Institute of R\&D for Biological Sciences

Elena MIHAI

National Institute of R\&D for Biological Sciences

Teodora CIUCAN

National Institute of R\&D for Biological Sciences

Adriana Florina POPESCU

HOFIGAL Export-Import S.A

Cristina LUNTRARU

HOFIGAL Export-Import S.A

Justinian TOMESCU

HOFIGAL Export-Import S.A

Oana CRACIUNESCU ( $\nabla$ oana_craciunescu2009@yahoo.com )

National Institute of R\&D for Biological Sciences

\section{Research Article}

Keywords: sage, rosemary, lavender, pesticide, antioxidant activity, acetylcholinesterase inhibition

Posted Date: January 28th, 2022

DOI: https://doi.org/10.21203/rs.3.rs-1288970/v1

License: (9) (i) This work is licensed under a Creative Commons Attribution 4.0 International License.

Read Full License 


\section{Abstract \\ Background}

Hydrosols are aqueous solutions obtained as by-products after essential oil extraction from aromatic plants. However, they have been lately reconsidered for applications in ecological agriculture, cosmetic and food industry due to their valuable bioactive phytochemicals content. The aim of this study was to identify the main volatile and polyphenolic compounds in hydrosols extracted from three Romanian Lamiaceae plants, sage (Salvia officinalis), rosemary (Rosmarinus officinalis) and lavender (Lavandula angustifolia) and to analyse the correlation of their total phenolics content to the antioxidant and acetylcholinesterase inhibition capacity, in view of future development of novel biopesticides.

\section{Results}

Our results showed that sage and rosemary hydrosols presented better antioxidant activity than lavender hydrosol in all tested free radical scavenging and metal chelating assays. Good correlation of the antioxidant activity to hydrosols' phenolics and flavonoids content was observed, except for DPPH assay. The same order was found for acetylcholinesterase activity inhibition, but this was partially related to phenolics content of hydrosols, suggesting that other components present in hydrosols were active compounds with synergistic role in this process.

\section{Conclusion}

These results indicated that Lamiaceae hydrosols could be recommended alone or as optimised mixtures to develop novel natural products for the control of pests in eco-agrosystems.

\section{Background}

Hydrosols or hydrolates are aqueous solutions obtained as by-products after essential oil extraction from herbs or spices [1]. Unlike essential oils, hydrosols contain the aqueous fraction of volatile compounds and polyphenols with bioactive properties [2]. Several studies showed that they are valuable extracts with potential applications in aromatherapy, preparation of cosmetic products, or cakes and drinks for food industry $[3,4]$. Moreover, hydrosols extracted from aromatic plant species belonging to Lamiaceae family, such as Mexican oregano (Poliomintha longiflora) [5], Polish lavender (Lavandula augustifolia) [6], Morrocan and Colombian thyme (Thymus vulgaris) [4, 7], Asteraceae family, such as Algerian marigold (Calendula arvensis) [8] and Rutaceae family, such as bitter orange (Citrus aurantium) flowers [9] have demonstrated antioxidant, antibacterial and antifungal activity.

The presence of bioactive phytochemicals, such as terpenes, phenols, alkaloids and the capacity to control the redox and neurologic processes indicated the potential of hydrosols to act as natural 
pesticides to prevent and limit a wide range of plant pathogens development, or their use as natural food sanitizers to preserve the product quality of fresh fruit and vegetables during storage [7-11]. However, these studies have analysed the volatile compounds and total phenolics content (TPC) of aromatic plant hydrosols, but information on their polyphenolic compounds composition was scarce and limited to characteristic ones.

Hydrosols containing phenolics, saponins and terpenes were previously tested for insecticide, toxicity and repellent activity against aphids, mites and beetles. Thus, sweet basil (Ocimum basilicum) and fringed rue (Ruta chalepensis) hydrosols had adverse effect on the reproduction and survival of Aphis gossypii aphid and Tetranychus urticae mite in leaf disk treatment [12], while lavender (Lavandula intermedia) hydrosol had similar activity to a synthetic repellent, but at $10^{3}$ times higher concentrations on Tribolium confusum beetle [13]. Hydrosols of two mint species (Mentha pulegium, Mentha suaveolens) showed a dose-dependent mortality of Toxoptera aurantii aphid in Petri biotests [14], while hydrosols of marjoram (Origanum majorana) and pennyroyal (Mentha pulegium) caused mortality of Myzus persicae aphids after $24 \mathrm{~h}$ of leaf disk exposure [15].

In addition, certain individual bioactive compounds isolated from solvent plant extracts and essential oils, such as the organic compound trans-cinnamic acid from Alpinia galanga hexane extract, the isoflavone rotenone extracted from Derris elliptica, the terpenoids azadirahtin from neem oil and pyrethrin from Chrysanthemum cinerariifolium, and veratrine alkaloids proved imbalance of nervous system functioning, weight reduction, behavior change and repellent effect against various insects [16-18]. To our knowledge, there are no reports describing the hydrosols' inhibitory activity on acetylcholinesterase (AChE), as main enzyme involved in neurotoxic processes and pesticide action or analyzing the correlation to phenolics content.

The aim of this study was to investigate the chemical composition of hydrosols obtained by steam distillation from three Romanian Lamiaceae species, sage ( $S$. officinalis), rosemary ( $R$. officinalis) and lavender ( $L$. angustifolia), in order to identify the main volatile and phenolic compounds using gas chromatography coupled with mass spectrometry (GC-MS) and high performance liquid chromatography (HPLC) techniques, respectively, and to analyze its correlation to the antioxidant activity and AChE activity inhibition, in order to be further used in novel formulations of biopesticides for pest control in agroecosystems. Special emphasis was given to analyzing the effect of hydrosols' polyphenolic content on their biological activity with applications in technologies for agriculture.

\section{Materials And Methods}

\section{Plant material and hydrosols preparation}

Aerial parts of sage (S. officinalis), rosemary ( $R$. officinalis) and lavender (L. angustifolia) from ecologic cultures were air-dried at $25^{\circ} \mathrm{C}$ to constant weight and powdered. Then, each powdered plant material (25

g) was placed in a round-bottomed flask, moistened in ultrapure water and extracted by steam distillation 
in ultrapure water $(750 \mathrm{ml})$, at $100^{\circ} \mathrm{C}$, for $2 \mathrm{~h}$ using a Clevenger-type extraction apparatus (J.P. Selecta, Spain). The essential oil was separated from the aqueous fraction representing the hydrosol, based on their density. The hydrosols were filtered and stored in the dark, at $4{ }^{\circ} \mathrm{C}$, until analysis.

\section{GC-MS analysis}

The analysis was performed on a Trace 1310 gas chromatograph, fitted with a capillary column (TGWAXMS, $30 \mathrm{~m} \times 0.25$ i.d. and $0.25 \mu \mathrm{m}$ film thickness) and equipped with a ISQ $7000 \mathrm{MS}$ detector (Thermo Scientific) combined with Chromeleon 7 Cromatography data system. The oven temperature was set to $40{ }^{\circ} \mathrm{C}$ for $10 \mathrm{~min}$ and then, increased up to $200^{\circ} \mathrm{C}$, at a rate of $4{ }^{\circ} \mathrm{C} / \mathrm{min}$. After the temperature reached $200{ }^{\circ} \mathrm{C}$, it was increased again up to $240{ }^{\circ} \mathrm{C}$, at $15{ }^{\circ} \mathrm{C} / \mathrm{min}$. The inlet was kept at $250{ }^{\circ} \mathrm{C}$ and the temperature of the MS detector for transfer line and ion source was $250^{\circ} \mathrm{C}$. The recording mass spectra range was set between $45-250 \mathrm{~m} / \mathrm{z}$. The samples were injected in split mode, using a split flow of 500 $\mathrm{ml} / \mathrm{min}$ and a split ratio of 333 . Helium was used as carrier gas at a flow rate of $1.5 \mathrm{ml} / \mathrm{min}$. Peak identification of main volatile compounds was based on retention time (RT) compared to that of the used standards and accomplished by computer software matching using NIST Tandem Mass Spectral Library version 2.4 .

\section{HPLC analysis}

HPLC analysis of polyphenolic compounds was carried out on a reverse phase column C18 Zorbax Eclipse XDB (150 x 4.6 i.d. mm) mounted on an Agilent 1200 HPLC system consisting of a quaternary pump, thermostated autosampler and diode array detector (Agilent, Germany). A sample (10 $\mu$ l) was injected and then eluted using mobile phase $A$ consisting of $2 \mathrm{mM}$ sodium acetate, $\mathrm{pH} 3$ and mobile phase $B$, acetonitrile, using the following gradient: $2-20 \%$ B, 0-30 min; $20-30 \% ~ B, 30-40$ min; $30 \% ~ B, 40-$ $50 \mathrm{~min} ; 30-2 \% \mathrm{~B}, 50-60 \mathrm{~min}$ [19]. The identification of compounds was performed by comparison to the RT of phenolic acids and flavonoids standards (Sigma) at 280 and $370 \mathrm{~nm}$. Quantification of the identified compounds was performed by peak area integration using standard curves built on the range of standard concentrations between $10-500 \mu \mathrm{g} / \mathrm{ml}$.

\section{Determination of total phenolic and flavonoid content}

TPC of each hydrosol was determined using the Folin-Ciocalteu assay [20]. Briefly, a volume of $150 \mu$ l sample was mixed with $750 \mu$ Folin-Ciocalteu reagent and incubated in the dark, for $5 \mathrm{~min}$. Then, $2 \mathrm{ml}$ of sodium carbonate solution $(12 \%, \mathrm{w} / \mathrm{w})$ and distilled water to reach $15 \mathrm{ml}$ were added, the mixture was vortexed and incubation continued at room temperature, for $30 \mathrm{~min}$. The OD was read at $765 \mathrm{~nm}$ using a V-650 UV-VIS spectrophotometer (Jasco, Japan). The standard curve was built using different concentrations of caffeic acid in the range of $0-500 \mu \mathrm{g} / \mathrm{ml}$. The results were expressed as $\mu \mathrm{g}$ caffeic acid equivalents (CAE) per g d.w.

Total flavonoids content (TFC) was evaluated by aluminium chloride assay, as previously described [21]. Briefly, hydrosol sample $(0.5 \mathrm{ml})$ was mixed with $1.5 \mathrm{ml}$ methanol, $0.1 \mathrm{ml}$ aluminum chloride solution 
$(10 \%, \mathrm{w} / \mathrm{w}), 0.1 \mathrm{ml}$ sodium acetate solution $(1 \mathrm{M})$ and $2.8 \mathrm{ml}$ distilled water. The mixture was incubated at room temperature, for $30 \mathrm{~min}$ and then the OD was read at $415 \mathrm{~nm}$ using a V-650 UV-VIS spectrophotometer (Jasco, Japan). The standard curve was built using quercetin solution in the range of concentrations $0-500 \mu \mathrm{g} / \mathrm{ml}$. The results were expressed as $\mu \mathrm{g}$ quercetin equivalents (QE) per $\mathrm{g}$ d.w.

\section{Determination of antioxidant activity}

\section{Trolox equivalent antioxidant capacity (TEAC) assay}

TEAC assay based on sample's ability to scavenge cationic free radicals of 2,2'-azino-bis(3ethylbenzothiazoline-6-sulfonic acid) (ABTS) was conducted according to previous protocol [22]. Briefly, ABTS stock solution was prepared by mixing $7 \mathrm{mM}$ ABTS solution with $2.45 \mathrm{mM}$ potassium persulfate in a ratio of 1:1 (v/v) and incubation in the dark, for $16 \mathrm{~h}$. The solution absorbance at $734 \mathrm{~nm}$ was brought to 0.7 by diluting in distilled water. Hydrosol samples $(100 \mu \mathrm{L})$ were mixed with $1 \mathrm{~mL}$ ABTS reagent and the optical density (OD) was measured at $734 \mathrm{~nm}$ after $10 \mathrm{~min}$ of incubation at room temperature, using a V-650 UV-VIS spectrophotometer (Jasco, Japan). The standard curve was built using Trolox, an analog of vitamin E with known antioxidant activity, in the range of concentrations $0-250 \mu \mathrm{M}$. The results were expressed as micromoles Trolox equivalents (TE) per $\mathrm{g}$ d.w.

\section{Cupric reducing antioxidant capacity (CUPRAC) assay}

The antioxidant activity against cupric ion was analysed according to a previous protocol [11] with minor modification. Briefly, $1 \mathrm{~mL} \mathrm{CuCl} 2$ solution $(10 \mathrm{mM})$ was mixed with $1 \mathrm{~mL}$ neocuproine $(7.5 \mathrm{mM})$ and $1 \mathrm{~mL}$ ammonium acetate buffer $(1 \mathrm{M}), \mathrm{pH}$ 7. After vortexing, the mixture was incubated at the room temperature, for $10 \mathrm{~min}$, to develop the complex. Then, $100 \mu \mathrm{L}$ of sample and $1 \mathrm{~mL}$ of distilled water were added and incubation continued at the room temperature, for $1 \mathrm{~h}$. The OD was read at $450 \mathrm{~nm}$ using a V650 UV-VIS spectrophotometer (Jasco, Japan). The blank was prepared by replacing the sample with distilled water. The standard curve was built using Trolox in the range of concentrations $0.1-1.0 \mathrm{mM}$. The results were expressed as micromoles TE per $\mathrm{g}$ d.w.

\section{DPPH free radical inhibition assay}

DPPH assay based on sample's capacity to inhibit the formation of 2,2-diphenyl-1-picrylhydrazyl (DPPH) free radicals was performed according to Sugahara et al. [23] protocol with slight modifications. Briefly, a volume of $1.35 \mathrm{~mL}$ DPPH methanolic solution $(0.25 \mathrm{mM})$ was mixed with $150 \mu \mathrm{L}$ test sample at different concentrations $(5-500 \mu \mathrm{g} / \mathrm{ml})$ and $0.9 \mathrm{~mL}$ Tris-HCl buffer $(0.1 \mathrm{M}), \mathrm{pH} 7.4$. The solutions were placed in the dark, for $30 \mathrm{~min}$ and the OD was read at $517 \mathrm{~nm}$ using a V-650 UV-VIS spectrophotometer (Jasco, Japan). The blank was prepared by replacing the sample with buffer. Controls of butylated hydroxytoluene (BHT) and ascorbic acid were similarly processed. The standard curve was built using Trolox in the range of concentrations $0.1-1.0 \mathrm{mM}$. The results of DPPH inhibition were calculated using the following formula: 
$\% \mathrm{DPPH}$ inhibition $=\left(\mathrm{OD}_{\text {blank }}-\mathrm{OD}_{\text {sample }}\right) / \mathrm{OD}_{\text {blank }} \times 100$

The IC50 values, representing the sample concentration that inhibited 50\% DPPH free radicals, were determined from the linear regression of DPPH inhibition vs. hydrosol concentration curve.

\section{Superoxide anion scavenging assay}

The measurement of superoxide radical scavenging was carried out according to Yang et al. [24] protocol with minor modification. Briefly, different concentrations of test samples $(5-1500 \mu \mathrm{g} / \mathrm{ml})$ were mixed with $3 \mathrm{ml}$ of Tris- $\mathrm{HCl}$ buffer $(50 \mathrm{mM}, \mathrm{pH} 8.2)$ and incubated at room temperature, for $10 \mathrm{~min}$. Then, $50 \mu \mathrm{L}$ of pyrogallol solution $(30 \mathrm{mM})$ were added and after $4 \mathrm{~min}$ of incubation at room temperature, the reaction was stopped by adding $300 \mu \mathrm{HCl}(8 \mathrm{M})$. The OD was measured at $325 \mathrm{~nm}$ using an UV/VIS spectrophotometer (Jasco V650, Japan). The blank was prepared by replacing pyrogallol solution with buffer. BHT and ascorbic acid were used as controls. The percentage of superoxide radical scavenging and IC50 values were calculated as in DPPH assay.

\section{Metal chelating assay}

The ferrous ion $\left(\mathrm{Fe}^{2+}\right)$ chelating activity was assessed based on complex formation with ferrozine in the presence of polyphenols, as described by Santos et al. [25], with minor modification. Briefly, various concentrations of each hydrosol $(75-3000 \mu \mathrm{g} / \mathrm{ml})$ in a volume of $50 \mu \mathrm{l}$ were added to $20 \mu \mathrm{L} \mathrm{FeSO}_{4}(0.3$ $\mathrm{mM}$ ) and $160 \mu \mathrm{l}$ distilled water and the mixture was incubated at room temperature, for $5 \mathrm{~min}$. Then, the reaction was initiated by adding $30 \mu$ ferrozine solution $(0.8 \mathrm{mM})$. The OD of the solution was measured after 15 min of incubation, at a wavelength of $562 \mathrm{~nm}$, using a microplate reader (BMG Labtech, Germany). The blank was prepared by replacing the ferrozine solution with distilled water. Ethylenediaminetetraacetic acid (EDTA) solution in a range of concentrations of $10-250 \mu \mathrm{g} / \mathrm{ml}$ was used as positive control. The percentage of metal ion chelating and IC50 values were calculated as in DPPH assay.

\section{Determination of in vitro inhibition of acetylcholinesterase}

An experimental model mimicking the neurotoxic effect of hydrosols on aphides through inhibition of AChE activity was developed to assess their biopesticide potential in vitro. The colorimetric assay based on thiocoline reaction with Ellman's reagent was performed using a 96-well microplate adapted protocol [26]. Briefly, $100 \mu \mathrm{l}$ 5,5'-dithiobis(2-nitrobenzoic acid) (DTNB) reagent (3 mM) was mixed in the wells of a microplate with $20 \mu \mathrm{l}$ of $\mathrm{AChE}(0.125 \mathrm{U} / \mathrm{mL})$ in Tris buffer $(50 \mathrm{mM}, \mathrm{pH}$ 8) containing $0.1 \%$ bovine serum albumin, and $20 \mu \mathrm{l}$ sample of different concentrations. The plate was incubated at $25^{\circ} \mathrm{C}$ with occasionally shaking, for $15 \mathrm{~min}$ and the OD was read at $412 \mathrm{~nm}$ (OD control) using a SpectroStar nano microplate reader (BMG Labtech, Germany). Then, $20 \mu \mathrm{l}$ of acetylthiocholine iodide $(7.5 \mathrm{mM})$ were added as enzymatic substrate and the hydrolysis reaction was followed by OD recording at $412 \mathrm{~nm}$, every 3 min, for $30 \mathrm{~min}$ (OD sample). A blank was similarly processed after sample replacement with an equal volume 
of buffer (OD blank). Quercetin solution was used as positive control. The results were calculated using the following formula:

$\%$ AChE inhibition $=1-(\mathrm{OD}$ sample $-\mathrm{OD}$ control $) /(\mathrm{OD}$ blank $-\mathrm{OD}$ control $) \times 100$

The IC50 values, representing the sample concentration that inhibited 50\% AChE activity, were also determined.

\section{Statistical analysis}

The experiments were performed in triplicate and the results were expressed as mean \pm standard deviation (SD) $(n=3)$. Statistical differences were calculated by two-tailed, equal variance Student $t$-test (Excel v.10) and they were considered significant at $p<0.05$.

\section{Results}

In this study, hydrosols were obtained as brown coloured solutions with pleasant odour by steam distillation of aerial parts of sage, rosemary and lavender and separation of essential oils. The extraction yield calculated for the aromatic plant hydrosols varied between $11.97 \pm 1.09 \%(\mathrm{w} / \mathrm{w})$ for sage, $12.07 \pm 0.77 \%$ for rosemary and $12.17 \pm 0.85 \%$ for lavender.

\section{Chemical composition of hydrosols}

Chemical analysis of the hydrosols carried out by GC-MS and the relative abundance of main volatile compounds is presented in Table 1. Sage hydrosol contained camphor (81.57\%) and thujone/isothujone (18.43\%). In rosemary hydrosol, six volatile compounds were detected and among them, camphor (37.52\%), verbenone (34.80\%) and eucalyptol (15.42\%) were the most abundant components. Lavender hydrosol presented a composition of volatile compounds rich in linalool $(29.03 \%)$ and derivatives (48.32\%), coumarine $(15.47 \%)$, a-terpineol $(14.21 \%)$ and caryophyllene oxide $(9.83 \%)$. The results indicated that steam distillation hydrosols contained cyclic monoterpenes and their oxygenated derivatives, more bioactive than acyclic ones. The composition was similar to that of corresponding essential oils (data not showed), but components distribution and abundance was lower.

Table 1. Chemical composition of volatile compounds of hydrosols prepared from aerial parts of sage, rosemary and lavender by steam distillation, determined by GC-MS analysis 


\begin{tabular}{|lllll|}
\hline No. & Compound & \multicolumn{3}{l}{ Relative area (\%) } \\
\cline { 3 - 5 } & & Sage & Rosemary & Lavender \\
\hline 1. & Camphene & - & 4.20 & - \\
\hline 2. & Eucalyptol (1,8-Cineole) & - & 15.42 & - \\
\hline 3. & Thujone & 15.02 & - & - \\
\hline 4. & Isothujone & 3.41 & - & - \\
\hline 5. & Camphor & 81.57 & 37.52 & - \\
\hline 6. & Linalool oxide & - & - & 6.85 \\
\hline 7. & trans-Linalool oxide & - & - & 5.97 \\
\hline 8. & Linalool & - & 2.07 & 29.03 \\
\hline 9. & Linalyl acetate & - & - & 6.47 \\
\hline 10. & Verbenone & - & 34.80 & - \\
\hline 11. & Borneol & - & 6.01 & - \\
\hline 12. & Terpinen-4-ol & - & - & 2.51 \\
\hline 13. & Crypton (4-isopropyl cyclohexanone) & - & - & 4.22 \\
\hline 14. & a-Terpineol & - & - & 14.21 \\
\hline 15. & Geraniol & - & - & 2.62 \\
\hline 16. & Caryophyllene oxide & - & - & 9.83 \\
\hline 17. & Cuminol & - & - & 2.82 \\
\hline 18. & Coumarin & & & 15.47 \\
\hline & & - & \\
\hline
\end{tabular}

The polyphenolic compounds were identified in HPLC chromatograms of sage, rosemary and lavender hydrosols based on their retention time. Their quantity determined by peak area integration is presented in Table 2. Rosmarinic acid, a characteristic compound was found in all hydrosols, in higher quantity in sage $(23.29 \mu \mathrm{g} / \mathrm{g}$ d.w.) and rosemary $(25.56 \mu \mathrm{g} / \mathrm{g}$ d.w.) hydrosols, while lavender hydrosol had a 5.15 $\mu \mathrm{g} / \mathrm{g}$ d.w. content. In sage hydrosol, caffeic $(7.08 \mu \mathrm{g} / \mathrm{g}$ d.w.) and ferulic $(10.7 \mu \mathrm{g} / \mathrm{g}$ d.w.) acids and the flavonoids rutin $(5.66 \mu \mathrm{g} / \mathrm{g}$ d.w.), quercetin $(16.05 \mu \mathrm{g} / \mathrm{g}$ d.w.) and the glycosylated derivatives of quercetin (isoquercetin, $2.77 \mu \mathrm{g} / \mathrm{g} \mathrm{d}$.w.), luteolin (cynaroside, $2.95 \mu \mathrm{g} / \mathrm{g} \mathrm{d.w}$.) and kaempferol (astragalin, $8.63 \mu \mathrm{g} / \mathrm{g}$ d.w.) were identified. Rosemary hydrosol contained the same compounds, but in different quantities, except for luteolin instead of its derivative. In lavender hydrosol, the flavonoids isoquercetin $(3.17 \mu \mathrm{g} / \mathrm{g}$ d.w.), astragalin (11.16 $\mu \mathrm{g} / \mathrm{g}$ d.w.) and luteolin $(7.4 \mu \mathrm{g} / \mathrm{g}$ d.w.) were quantified, in addition to caffeic (4.8 $\mu \mathrm{g} / \mathrm{g}$ d.w.) and ferulic $(4.89 \mu \mathrm{g} / \mathrm{g}$ d.w.) acids. 
Table 2. Chemical composition of polyphenolic compounds of hydrosols prepared from aerial parts of sage, rosemary and lavender by steam distillation, determined by HPLC analysis

\begin{tabular}{|lllll|}
\hline No. & Compound & $\begin{array}{l}\text { Sage } \\
(\mu \mathrm{g} / g \text { d.w. })\end{array}$ & $\begin{array}{l}\text { Rosemary } \\
(\mu \mathrm{g} / g \text { d.w. })\end{array}$ & $\begin{array}{l}\text { Lavender } \\
(\mu \mathbf{g} / \mathbf{g} \text { d.w. })\end{array}$ \\
\hline 1. & Gallic acid & - & - \\
\hline 2. & Chlorogenic acid & - & - & - \\
\hline 3. & Caffeic acid & 7.08 & 5.35 & 4.80 \\
\hline 4. & Ferulic acid & 10.70 & 0.86 & 4.89 \\
\hline 5. & Rosmarinic acid & 23.29 & 25.56 & 5.15 \\
\hline 6. & Rutin & 5.66 & 8.32 & - \\
\hline 7. & Quercetin 3-glucoside (Isoquercetin) & 2.77 & 6.85 & 3.17 \\
\hline 8. & Luteolin 7-glucoside (Cynaroside) & 2.95 & - & - \\
\hline 9. & Kaempferol 3-glucoside (Astragalin) & 8.63 & 6.52 & 11.16 \\
\hline 10. & Quercetin & 16.05 & 16.33 & - \\
\hline 11. & Luteolin & - & 7.60 & 7.40 \\
\hline 12. & Kaempferol & - & - & - \\
\hline
\end{tabular}

The values of TPC and TFC in steam distillation hydrosols of sage, rosemary and lavender are presented in Table 3. The data showed that sage hydrosol had the highest TPC (325.49 $\mu \mathrm{g}$ CAE/g d.w.), followed in descending order by rosemary $(267.11 \mu \mathrm{g} \mathrm{CAE} / \mathrm{g}$ d.w.) and lavender $(216.36 \mu \mathrm{g} \mathrm{CAE} / \mathrm{g}$ d.w.) hydrosols. The same variation was observed for flavonoids content, but sage hydrosol had two times higher value (59.32 $\mu \mathrm{g} \mathrm{QE/g} \mathrm{d.w.)} \mathrm{than} \mathrm{that} \mathrm{of} \mathrm{rosemary}(29.28 \mu \mathrm{g}$ QE/g d.w.) and lavender (26.55 $\mu \mathrm{g} \mathrm{QE/g} \mathrm{d.w.)}$ hydrosols.

Table 3. Total phenolic (TPC) and flavonoids (TFC) content and antioxidant activity as TEAC and CUPRAC determined for sage, rosemary and lavender hydrosols obtained by steam distillation 


\begin{tabular}{|c|c|c|c|c|}
\hline Plant hydrosol & $\begin{array}{l}\text { TPC }^{\mathrm{a}} \\
(\mu \mathrm{g} \mathrm{CAE} / \mathrm{g} \text { d.w. })\end{array}$ & $\begin{array}{l}\text { TFC }^{\mathrm{b}} \\
(\mu \mathrm{g} \mathrm{QE} / \mathrm{g} \text { d.w. })\end{array}$ & $\begin{array}{l}\text { TEAC }^{c} \\
(\mu \mathrm{M} \text { TE/g d.w.) }\end{array}$ & $\begin{array}{l}\text { CUPRAC }^{c} \\
(\mu \mathrm{M} T E / g \text { d.w.) }\end{array}$ \\
\hline Sage & $325.49 \pm 17.05$ & $59.32 \pm 0.64$ & $2.09 \pm 0.07$ & $4.33 \pm 0.20$ \\
\hline Rosemary & $267.11 \pm 19.70 *$ & $29.28 \pm 1.93^{*}$ & $1.84 \pm 0.09$ & $3.73 \pm 0.15$ \\
\hline Lavender & $216.36 \pm 13.84^{*}$ & $26.55 \pm 0.24 *$ & $1.17 \pm 0.03^{*}$ & $2.77 \pm 0.23^{*}$ \\
\hline
\end{tabular}

a-expressed as caffeic acid equivalents (CAE), b-expressed as quercetin equivalents (QE), c-expressed as Trolox equivalents (TE), ${ }^{*}<<0.05$, compared to sage hydrosol.

\section{Antioxidant activity of hydrosols}

In this study, the screening of the antioxidant activity of each hydrosol was performed using four assays with mechanism of ROS scavenging, based on hydrogen atom transfer (HAT) (TEAC assay), single electron transfer (SET) (CUPRAC assay) and mixed mode of action (DPPH and superoxide assays), and one with mechanism of metal ions chelating. The results of ABTS radical scavenging, as well as $\mathrm{Cu}^{2+}$ ion reducing capacity, expressed as Trolox equivalents (TE) are presented in Table 3. The steam distillation hydrosols of sage (2.09 $\mu \mathrm{M} \mathrm{TE} / \mathrm{g}$ d.w.) and rosemary (1.84 $\mu \mathrm{M} \mathrm{TE} / \mathrm{g} \mathrm{d.w.})$ had significantly $(p<0.05)$ higher TEAC than lavender hydrosol $(1.17 \mu \mathrm{M}$ TE/g d.w.). Similar, CUPRAC varied in the following ascending order: lavender<rosemary<sage, with values between 2.77-4.33 $\mu \mathrm{M} \mathrm{TE} / \mathrm{g}$ d.w.

The correlation of hydrosols antioxidant activity with each TPC and TFC value is presented in Figure 1A. The TEAC and CUPRAC correlated in a linear, positive manner to TPC of aromatic plants hydrosols obtained by steam distillation, with coefficient values of $R^{2}=0.89$ and $R^{2}=0.96$, respectively. The antioxidant activity also correlated to the flavonoids content of hydrosols, but lower coefficients of $\mathrm{R}^{2}=0.55$ for TEAC and $\mathrm{R}^{2}=0.69$ for CUPRAC were observed. This analysis confirmed that the increasing content of polyphenolic compounds, the more significant antioxidant activity of the hydrosol, probably due to higher number of hydroxyl groups.

The antioxidant activity of hydrosols obtained by steam distillation was also determined by their scavenging capacity of free DPPH radicals and superoxide species also found in living cells, and their metal $\left(\mathrm{Fe}^{2+}\right)$ chelating capacity. The results obtained at different sample concentrations are showed in Figures $2 \mathrm{~A}-\mathrm{C}$. The percentage of free DPPH radicals inhibition increased in a dose-dependent manner in the presence of hydrosols (Figure 2A). All plant hydrosols showed stronger DPPH scavenging capacity, compared to the positive controls BHT (58\%) and ascorbic acid (31\%), reaching $70-85 \%$ at $500 \mu \mathrm{g} / \mathrm{ml}$. Rosemary hydrosol exhibited the highest antioxidant activity as also showed by IC50 calculated value of $252.33 \mu \mathrm{g} / \mathrm{ml}$, followed by sage $(264.14 \mu \mathrm{g} / \mathrm{ml})$ and lavender $(333.75 \mu \mathrm{g} / \mathrm{ml})$ hydrosols (Table 4$)$.

In superoxide anion scavenging assay, ascorbic acid was the most efficient antioxidant agent, reaching $93 \%$ inhibition at a concentration of $250 \mu \mathrm{g} / \mathrm{ml}$ (Figure 2B). Rosemary and sage hydrosols presented 25- 
$40 \%$ inhibition capacity in the range of concentrations $10-250 \mu \mathrm{g} / \mathrm{ml}$. At higher concentrations, a steep increase of the antioxidant activity was observed, reaching values of $65-86 \%$ superoxide inhibition, similar to BHT (99\%) at $1500 \mu \mathrm{g} / \mathrm{ml}$ (Figure 2B). Lavender hydrosol showed lower capacity to quench superoxid anions (13\% inhibition) in the range of concentrations $10-500 \mu \mathrm{g} / \mathrm{ml}$ and then, the activity suddenly increased up to $93 \%$ at $1500 \mu \mathrm{g} / \mathrm{ml}$. The IC50 values of sage $(622.12 \mu \mathrm{g} / \mathrm{ml})$, rosemary $(1051.77 \mu \mathrm{g} / \mathrm{ml})$ and lavender $(985.02 \mu \mathrm{g} / \mathrm{ml})$ hydrosols were significantly $(p<0.05)$ higher, compared to BHT $(472.95 \mu \mathrm{g} / \mathrm{ml})$ and ascorbic acid $(116.22 \mu \mathrm{g} / \mathrm{ml})$ controls (Table 4), indicating lower antioxidant capacity of steam distillation hydrosols towards superoxide anion.

The metal chelating capacity of tested hydrosols varied in a dose-dependent manner. Unlike the free radicals inhibition capacity, the metal chelating activity took place at high concentrations of hydrosols, ranging between $500-3000 \mu \mathrm{g} / \mathrm{ml}$, reaching values of $70 \%$ (Figure $2 \mathrm{C}$ ). Sage hydrosol was the best $\mathrm{Fe}^{2+}$ ions chelator, followed by rosemary and lavender hydrosols with similar activity. The IC50 value of sage $(502.10 \mu \mathrm{g} / \mathrm{ml})$ was significantly $(\mathrm{p}<0.05)$ lower than those of rosemary $(2442.10 \mu \mathrm{g} / \mathrm{ml})$ and lavender $(2557.15 \mu \mathrm{g} / \mathrm{ml})$ hydrosols, indicating better chelating capacity. IC50 values of all hydrosols were significantly $(\mathrm{p}<0.05)$ higher, compared to EDTA $(41.50 \mu \mathrm{g} / \mathrm{mL})$, a known metal chelating agent (Table 4).

Table 4. IC50 values calculated for free DPPH radicals and superoxide anion scavenging, metal chelating and acetylcholinesterase (AChE) inhibition assays in the presence of sage, rosemary and lavender hydrosols, compared to BHT, ascorbic acid, EDTA and quercetin, used as controls

\begin{tabular}{|c|c|c|c|c|}
\hline \multirow{2}{*}{$\begin{array}{l}\text { Plant } \\
\text { hydrosol }\end{array}$} & \multicolumn{3}{|l|}{ IC50 ( $\mathrm{gg} / \mathrm{ml})$} & \multirow{2}{*}{$\begin{array}{l}\text { IC50 (mg/ml) } \\
\text { AChE inhibition } \\
\text { assayc }^{c}\end{array}$} \\
\hline & $\begin{array}{l}\text { DPPH scavenging } \\
\text { assay }^{\mathrm{a}}\end{array}$ & $\begin{array}{l}\text { Superoxide anion } \\
\text { scavenging assay }^{\mathrm{a}}\end{array}$ & $\begin{array}{l}\text { Metal chelating } \\
\text { assay }^{\mathrm{b}}\end{array}$ & \\
\hline Sage & $264.14 \pm 14.24^{\star}$ & $622.12 \pm 28.27 *$ & $\begin{array}{c}502.10 \pm \\
30.39^{*}\end{array}$ & $7.48 \pm 0.90$ \\
\hline Rosemary & $252.33 \pm 12.87^{\star}$ & $1051.77 \pm 48.36^{*}$ & $\begin{array}{l}2442.10 \pm \\
124.18 \text { * }\end{array}$ & $6.23 \pm 0.77$ \\
\hline Lavender & $333.75 \pm 17.35^{\star}$ & $985.02 \pm 45.12^{*}$ & $\begin{array}{l}2557.15 \pm \\
101.72^{\star}\end{array}$ & $15.08 \pm 1.14^{\star}$ \\
\hline BHT & $449.80 \pm 23.42^{\star}$ & $472.95 \pm 22.65^{\star}$ & - & - \\
\hline $\begin{array}{l}\text { Ascorbic } \\
\text { acid }\end{array}$ & $851.78 \pm 38.56$ & $116.22 \pm 4.38$ & - & - \\
\hline EDTA & - & - & $41.50 \pm 3.88$ & - \\
\hline Quercetin & - & - & - & $5.62 \pm 0.39$ \\
\hline
\end{tabular}

${ }^{*} \mathrm{p}<0.05$, compared to ascorbic acid (a), EDTA (b) and quercetin (c) solutions

The calculated IC50 values were linear and positively correlated to the content of flavonoid compounds in metal chelating $\left(R^{2}=0.99\right)$ and superoxide anion scavenging $\left(R^{2}=0.92\right)$ assays, while lower correlation 
coefficients of $R^{2}=0.81$ and $R^{2}=0.63$ were found vs. TPC (Figure 1B). Low correlation coefficients of IC50 with phenolics content $\left(R^{2}=0.52\right)$ and particularly, with flavonoids content $\left(R^{2}=0.18\right)$ were observed in DPPH assay.

\section{Inhibition of AChE activity}

The results of AChE activity inhibition in the presence of hydrosols are showed in Figure 3A, while the calculated IC50 values are given in Table 4. The data showed that the hydrosols obtained by steam distillation of Lamiaceae plants exerted an increasing enzyme activity inhibition in a dose-dependent manner, in the concentration range between $0.625-5 \mathrm{mg} / \mathrm{ml}$. The most effective hydrosol with neurotoxic potential on pests was that obtained from rosemary (42.49\%) and the value of AChE inhibition was close to that of quercetin solution (46.22\%) at $5 \mathrm{mg} / \mathrm{ml}$. Sage and rosemary hydrosols presented a steep increase of AChE activity inhibition with 160-400\% higher values at $5 \mathrm{mg} / \mathrm{ml}$ as against $2.5 \mathrm{mg} / \mathrm{ml}$, while lavender hydrosol presented $130 \%$ increase, reaching a value of $25 \%$ AChE inhibition. The IC50 value of rosemary hydrosol $(6.23 \mathrm{mg} / \mathrm{ml})$ was close to that of sage $(7.48 \mathrm{mg} / \mathrm{ml})$ and both were significantly $(p<0.05)$ lower than that of lavender hydrosol $(15.08 \mathrm{mg} / \mathrm{ml})($ Table 4$)$, indicating higher neurotoxic potential.

A correlation coefficient of $R^{2}=0.59$ was obtained for IC50 value of AChE activity inhibition vs. TPC, while a low coefficient of $R^{2}=0.20$ was obtained vs. TFC (Figure 3B). Overall, the values of AChE activity inhibition of Lamiaceae hydrosols showed lower correlation to TPC and particularly, to TFC in comparison to their antioxidant activity, indicating an equal role of other compounds in order to exert a neurotoxic effect.

\section{Discussion}

This study aimed to investigate the antioxidant and biopesticide potential of three hydrosols obtained by steam distillation of Lamiaceae plants (sage, rosemary, lavender), as alternative natural products to synthetic pesticides, and intended for ecological protection of agricultural crops, low risk of developing pest resistance and sustainable management of soil and environment. In the same time, valorization of by-products in the form of hydrosols represents a biotechnological advantage.

Unlike essential oils, hydrosols contain low amount of volatile compounds. However, this could be a plus in terms of reduced toxicity when used as natural pesticides. Several investigators have studied the volatile compounds of Lamiaceae hydrosols, revealing different compositions. The variability of the volatile profile of plant extracts depends on various factors, like agronomic practices, climatic changes, species, regions and extraction method $[10,27]$. Thus, camphor was the major compound found in hydrosols obtained by steam distillation of Moroccan (51\%) and Turkish (43.38\%) sage, being followed by 1,8-cineole (24\%), thujone (12.9\%) and cis-thujone (15.46\%), respectively [4, 27]. Similar, a recent study revealed that the most abundant constituents of Italian sage hydrosol were 1,8-cineole (61.4\%), camphor (22.5\%) and a-thujone (8.4\%), but presented different proportions [28]. Besides these volatile compounds, 
sage hydrosol also contained linalool (13.41\%), $\delta$-cadinene (10.18\%) and carvacrol (8.96\%) [10], borneole $(7.66 \%)$, humulene oxide $(1.12 \%)$ and myrtenol $(0.55 \%)$ [27]. These results were consistent with those in the present study, reporting camphor and thujone as main volatile components of Romanian sage hydrosol prepared by steam distillation. This was a similar composition to that of the essential oil extracted from S. officinalis, but presented a different distribution of volatile compounds [29].

Rosemary hydrosols obtained by various steam distillation procedures contained camphor (41-51.9\%) and 1,8-cineole (29.30-38.20\%), as main volatile compounds, and lower percentage of verbenone (1.8$4.2 \%)$, borneol (7.4\%), terpinen-4-ol (3.4\%) and 3-octanone (2.1-3.2\%) [7, 30]. Other studies reported the prevalence of terpinen-4-ol (51.9\%), 1,8-cineole (50.25\%) or verbenone $(45.31 \%)$ in the chemical profile of rosemary hydrosols, according to the geographical region of rosemary cultivation in Italy [31], Morocco [4], Colombia [32] or Korea [33]. Moreover, the chemical profile of rosemary hydrosols varied in relation to the harvesting season, exhibiting similar proportion of aroma components, such as camphor (24.9\%), aterpineol (21.19\%) and borneol (20.4\%) when harvested in August [30]. Our findings strengthen these results, showing that camphor, 1,8-cineole and verbenone were present as main volatile compounds in Romanian rosemary hydrosol prepared by steam distillation.

Linalool was found as major compound in hydrosols from lavender harvested from Moroccan (45\%), Italian (42.9\%) and Polish (26.5\%) regions [4, 31, 34]. Linalool content (39.2-53.0\%) can also vary according to the source represented by fresh or dried flowers or herbs [35] and the used distillation method, such as hydrodistillation (23.2\%) or steam distillation (7.9\%) [36]. The main volatile compounds identified in the ISO standard and analysed in lavender essential oils were linalyl acetate (36.55\%), linalool (31.17\%), cis- $\beta$-ocimene (3.33\%), lavandulyl acetate (1.86\%), 1-octen-3-yl acetate (1.64\%), 1,8cineole $(1.46 \%)$ and camphor (0.53\%) [37]. Comparison of distillation extracts from Italian L. intermedia showed that the major compound of the essential oil, linalyl acetate, was changed with linalool and linalool oxide in the hydrosol of the same species, being completed by lower percentage of 1,8-cineole, camphor, geraniol and borneol [13]. Our results were consistent with previous studies, indicating a broad distribution of several volatile components in lavender hydrosol prepared by steam distillation, with linalool and derivatives, a-terpineol and terpinen-4-ol, and coumarin as main compounds.

As by-products of hydrodistillation, the hydrosols obtained from aerial flowering parts of aromatic plants of the Lamiaceae family showed lower TPC and TFC values, compared to those reported for solvent plant extracts. Thus, compared to literature, sage hydrosol prepared in our study had 18 to 190 times lower TPC than the methanolic [38] and aqueous extract of $S$. officinalis [39], respectively. Similar, rosemary hydrosol had 125 and 700 times lower TPC and TFC, respectively, compared to the methanolic extract [40]. The lavender hydrosol prepared in our study had $216.36 \mu \mathrm{g} / \mathrm{g}$ d.w. TPC and $26.55 \mu \mathrm{g} / \mathrm{g}$ d.w. TFC, while the corresponding values in methanolic lavender extract reached $4.06 \mathrm{mg} / \mathrm{g} \mathrm{d.w} \mathrm{TPC}$ and $3.51 \mathrm{mg} / \mathrm{g} \mathrm{d} . \mathrm{w}$. TFC [41]. On the other hand, our study showed that sage hydrosol had the highest TPC and TFC values, while rosemary and lavender hydrosols presented comparable values, similar to a recent report of Jakubczyk et al. [42]. Furthermore, our HPLC analysis of sage, rosemary and lavender hydrosols showed the presence of ferulic and caffeic acids, while flavonoids quercetin and luteolin were present as aglycones and 
glycosylated derivatives, isoquercetin and cynaroside, together with kaempferol 3-glucoside (astragalin). No reports were found in the literature investigating the chemical composition of hydrosols by HPLC, unlike the corresponding solvent plant extracts, except for solely specific compounds.

Reactive oxygen species (ROS) (hydroxyl, superoxide, singlet oxygen, hydrogen peroxide) are naturally formed as a result of the metabolic activity of normal or inflamed cells, or in response to aggressive environmental factors, such as pesticides, pollutants, organic solvents, radiation, smoking [43]. It is known that plants contain antioxidant compounds, including polyphenolic compounds and volatile oils, which catalyze the transformation of ROS into stable products, favoring the ability to defend against oxidative stress, at the cellular and molecular level. In addition, the metal chelating ability plays an important role in disrupting the chain of ROS propagation. Polyphenolic compounds, in particular phenolic acids and flavonoids presenting aromatic rings substituted in ortho- and para- position, demonstrated antioxidant activity and plant protection against aggression by environmental factors [44], but no studies correlated their presence in hydrosols obtained as by-products to the consistent ROS scavenging capacity. The latter was mostly linked to the presence of water soluble compounds of essential oils, such as 1,8-cineole and linalool, with established antioxidant activity $[4,6]$ and also found in rosemary and lavender hydrosols from our study. The major oxygenated monoterpenes, like camphor and thujone, also detected in our sage hydrosol exhibited weaker scavenging activity, compared to positive controls [45]. These observations could indicate lavender hydrosol as better antioxidant agent than rosemary and sage hydrosols, as previously reported after TEAC and superoxide scavenging assessment [4]. Despite volatile composition and in view of our analyses, a linear, positive correlation between TPC, TFC values and the antioxidant activity was found in all tested methods, except for DPPH assay, indicating sage hydrosol as the best distillation extract, closely followed by rosemary hydrosol. Similar results were reported for the Italian sage and rosemary hydrosols obtained by steam distillation, with better IC50 values of free DPPH radicals inhibition, compared to lavender hydrosol [28, 31]. High correlation coefficients were found in our study for TEAC and CUPRAC assays vs. TPC, while superoxide and metal chelating correlated well to TFC. The differences reported in all these studies could be explained by the chemical composition variability of each hydrosol, as complex mixture of monoterpenes, but also containing plant water-soluble secondary metabolites, like polyphenolic compounds, all contributing to the antioxidant activity, but in better correlation to the latter.

To the best of our knowledge, this is the first report on the potential of aromatic plant hydrosols to inhibit AChE activity and the correlation to TPC and TFC values. AChE enzyme is involved in termination of synaptic transmission in vivo by rapid hydrolysis of the neurotransmitter acetylcholine to choline and acetic acid, causing disturbances in pest development [46]. The mechanism for AChE activity inhibition was attributed to high concentrations of monoterpenoids based on chloride channels activity alteration through octopaminergic pathways, changing the neurohormonal levels, the gustatory and olfactory response $[47,48]$. Another mechanism of inhibition of AChE activity described in particular for alkaloids and saponins was based on their binding to the amino acids from the enzyme active site and modulation of sodium channels, slowing down their functioning and affecting the cytoplasmic calcium level, which led to neurological effects [17]. 
AChE inhibitory potential was previously investigated only for essential oils and solvent plant extracts of the studied species, showing variation in relation to the method of extraction. Thus, essential oil of rosemary ( $R$. officinalis) prevailed over different solvent (methanol, petroleum ether, chloroform, ethyl acetate) extracts as effective AChE activity inhibition [49] and the same observation was reported for sage (S. officinalis) and lavender (L. angustifolia) essential oils, compared to ethanolic and aqueous extracts [50]. In addition, individual monoterpenes and polyphenolic compounds presented AChE inhibitory potential, which varied in a dose-dependent manner, but not all compounds were biologically active. Only a few volatile compounds were potent AChE inhibitors [51], while some demonstrated insecticidal effect [52]. Thus, the main monoterpene possessing good anti-AChE effect was 1,8-cineole [53] and its increasing amount in sage essential oils improved the AChE inhibition [54]. In our study, 1,8cineole was present in high proportion in rosemary hydrosol presenting good AChE inhibition and indicating its potential toxicity on insects. However, no activity towards AChE was determined for camphor and linalool [53], the major compounds detected in our study in sage/rosemary and lavender hydrosols, respectively. Other monoterpenes, like $\beta$-pinene and borneol found in $S$. officinalis essential oil contributed to AChE activity inhibition [55], but they were not detected in Romanian sage hydrosol.

On the other hand, some of the volatile compounds demonstrated pesticide activity. Thus, the cyclic monoterpene 1,8-cineole present in rosemary hydrosol and camphor detected in high proportion in sage and rosemary hydrosols, had unpleasant odour and were classified as insect repellents and antifeedants $[13,56]$. In turn, terpinen-4-ol, a monoterpene alcohol, and linalool, an acyclic terpene alcohol, detected in lavender hydrosol, were previously reported to have herbicide potential, acting as phytotoxic agents for weed germination inhibition [13]. In accordance, our results indicated that sage and rosemary hydrosols had higher pesticide potential than lavender hydrosol, determined as in vitro AChE inhibition activity.

The inhibitory effect on AChE activity was also reported for individual phenolic acids, in the following order rosmarinic acid>caffeic acid>gallic acid=chlorogenic acid>homovanillic acid>sinapic acid [57, 58], but also for ferulic and chlorogenic acid [59]. Flavonoids, like quercetin, kaempferol and, in a lesser extent, luteolin were also reported as efficient AChE inhibitors $[57,60]$ and were detected as such or in their glycosylated forms in all hydrosols analysed in this study. A previous study showed that the ethanolic extract of $S$. officinalis, rich in phenolic compounds, had higher AChE inhibition rate than $R$. officinalis and L. angustifolia extracts [59]. Our findings showed similar variation of the biopesticide potential of the studied hydrosols of sage, rosemary and lavender. Analysis of correlation to their TPC and TFC values indicated lower coefficients than for the antioxidant activity and the possibility that polyphenolic, volatile and other compounds found in hydrosols could have synergistic action on AChE activity inhibition.

\section{Conclusion}

Our results showed that sage and rosemary hydrosols were more effective antioxidants in comparison to lavender hydrosol. The antioxidant activity of Lamiaceae hydrosols obtained by steam distillation was highly correlated to the phenolics and flavonoids content, as demonstrated by free radical scavenging and metal chelating assays, except for DPPH assay. The poor relationship of AChE inhibition activity to 
phenolics and especially, the flavonoids content of hydrosols suggested that some other bioactive compounds could play a role in this important process defining the pesticide potential. Based on all these results, mixtures of Lamiaceae hydrosols could be developed in a future study as useful biopesticide formulas for the treatment and control of pests in eco-agrosystems.

\section{Abbreviations}

TPC

total phenolics content

AChE

acetylcholinesterase

GC-MS

gas chromatography coupled with mass spectrometry

HPLC

high performance liquid chromatography

CAE

caffeic acid equivalents

QE

quercetin equivalents

TFC

total flavonoids content

TEAC

Trolox equivalents antioxidant capacity

ABTS

2,2'-azino-bis(3-ethylbenzothiazoline-6-sulfonic acid

OD

optical density

TE

Trolox equivalents

CUPRAC

Cupric reducing antioxidant capacity

DPPH

2,2-diphenyl-1-picrylhydrazyl

$\mathrm{BHT}$

butylated hydroxytoluene

EDTA

ethylenediaminetetraacetic acid

DTNB

5,5'-dithiobis(2-nitrobenzoic acid)

SD 
standard deviation

HAT

hydrogen atom transfer

SET

single electron transfer

ROS

reactive oxygen species.

\section{Declarations}

\section{Acknowledgements}

Not applicable.

\section{Authors'contributions}

AGP and OC designed the experiments, supervised the study, wrote and reviewed the manuscript. EM, TC, AFP, JT undertook sample analysis, analysed and interpreted the data and contributed to the writing of the manuscript. CL contributed to the design and writing of this manuscript. All authors read and approved the final manuscript.

\section{Funding}

This work was supported by a national grant of the CCCDI-UEFISCDI, project no. PN-III-P2-2.1-PED-20193561, within PNCDI III, Ministry of Research and Digitization.

\section{Availability of data and materials}

The datasets used and/or analysed during the current study are available from the corresponding author on reasonable request.

\section{Ethics approval and consent to participate}

Not applicable.

\section{Consent for publication}

Not applicable.

\section{Competing interests}

The authors declare that they have no financial and non-financial competing interests.

\section{References}


1. Acimovic MG, Tesevic VV, Smiljanic KT, Cvetkovic MT, Stankovic JM, Kiprovski BM, Sikora VS. Hydrolates: by-products of essential oil distillation: chemical composition, biological activity and potential uses. Adv Technol. 2020;9:54-70.

2. D'Amato S, Serio A, Lopez CC, Paparella A. Hydrosols: biological activity and potential as antimicrobials for food applications. Food Control. 2018;86:126-37.

3. Paolini J, Leandri C, Desjobert JM, Barboni T, Costa J, Comparison of liquid-liquid extraction with headspace methods for the characterization of volatile fractions of commercial hydrolates from typically mediterranean species. J Chromatogr A. 2008;1193:37-49.

4. Aazza S, Miguel MG. Antioxidant activity of some Morrocan hydrosols. J Med Plant Res. 2011;5:6688-96.

5. Cid-Perez TS, Avila-Sosa R, Ochoa-Velasco CE, Rivera-Chavira BE, Nevarez-Moorillon GV. Antioxidant and antimicrobial activity of Mexican oregano (Poliomintha longiflora) essential oil, hydrosol and extracts from waste solid residues. Plants. 2019;8:22.

6. Prusinowska R, Smigielski K, Stobiecka A, Kunicka-Styczynska A. Hydrolates from lavender (Lavandula angustifolia) - their chemical composition as well as aromatic, antimicrobial and antioxidant properties. Nat Prod Res. 2016;30:386-93.

7. Hay YOM, Abril Sierra MA, Tellez M, Sequeda CLG, Tellez AAN, Bonnafous C, Raynaud C. Phytochemical, antioxidant and antimicrobial parameters of essential oils and hydrosols of Colombian thyme and rosemary obtained using two different steam distillation methods. Int $\mathrm{J}$ Phytocos Nat Ingred. 2015;2:7.

8. Belabbes R, Dib MEA, Djabou N, llias F, Tabti B, Costa J, Muselli A. Chemical variability, antioxidant and antifungal activities of essential oils and hydrosol extract of Calendula arvensis $\mathrm{L}$. from Western Algeria. Chem Biodiv. 2017;14:e1600482.

9. Degirmenci H, Erkurt H. Relationship between volatile components, antimicrobial and antioxidant properties of the essential oil, hydrosol and extracts of Citrus aurantium L. flowers. J Infect Public Health. 2020;13:58-67.

10. Tornuk F, Cankurt H, Ozturk I, Sagdic O, Bayram O, Yetim H. Efficacy of various plant hydrosols as natural food sanitizers in reducing Escherichia coli 0157:H7 and Salmonella typhimurium on fresh cut carrots and apples. Int J Food Microbiol. 2011;148:30-5.

11. Georgiev V, Ananga A, Dincheva I, Badjakov I, Gochev V, Tsolova V. Chemical composition, in vitro antioxidant potential, and antimicrobial activities of essential oils and hydrosols from native American muscadine grapes. Molecules. 2019;24:3355-67.

12. Traka CK, Petrakis EA, Kimbaris AC, Polissiou MG, Perdikis DC. Effects of Ocimum basilicum and Ruta chalepensis hydrosols on Aphis gossypii and Tetranychus urticae. J Appl Entomol. 2018;142:413-20.

13. Politi M, Menghini L, Conti B, Bedini S, Farina P, Cioni PL, Braca A, Leo M de. Reconsidering hydrosols as main products of aromatic plants manufactory: the lavandin (Lavandula intermedia) case study in Tuscany. Molecules. 2020;25:2225. 
14. Zekri N, Handaq N, Caidi AE, Zair T, Belghiti MAE. Insecticidal effect of Mentha pulegium L. and Mentha suaveolens Ehrh. hydrosols against a pest of citrus, Toxoptera aurantii (Aphididae). Res Chem Intermed. 2016;42:1639-49.

15. Petrakis EA, Kimbaris AC, Lykouressis DP, Polissiou MG, Perdikis DC. Hydrosols evaluation in pest control: insecticidal and settling inhibition potential against Myzus persicae (Sulzer). J Appl Entomol. 2015;139:260-67.

16. Poonsri W, Pengsook A, Pluempanupat W, Yooboon T, Bullangpoti V. Evaluation of Alpinia galanga (Zingiberaceae) extracts and isolated trans-cinnamic acid on some mosquitoes larvae. Chem Biol Technol Agric. 2019;6:17.

17. Spochacz M, Chowanski S, Walkowiak-Nowicka K, Szymczak M, Adamski Z. Plant-derived substances used against beetles-pests of stored crops and food and their mode of action: a review. Compr Rev Food Sci Food Saf. 2018;17:1339-66.

18. Hernandez-Carlos B, Gamboa-Angulo M. Insecticidal and nematicidal contributions of Mexican flora in the search for safer biopesticides. Molecules. 2019;24:897-931.

19. Craciunescu O, Constantin D, Gaspar A, Toma L, Utoiu E, Moldovan L. Evaluation of antioxidant and cytoprotective activities of Arnica montana L. and Artemisia absinthium L. ethanolic extracts. Chem Cent J. 2012;6:97.

20. Moldovan L, Gaspar A, Toma L, Craciunescu O, Saviuc C. Comparison of polyphenolic content and antioxidant capacity of five Romanian traditional medicinal plants. Rev. Chim. 2011;62: 299-305.

21. Gaspar A, Craciunescu O, Trif M, Moisei M, Moldovan L. Antioxidant and anti-inflammatory properties of active compounds from Arnica montana L. Rom Biotechnol Lett. 2014;19:9353-65.

22. Savin S, Craciunescu O, Oancea A, llie D, Ciucan T, Antohi LS, Toma A, Nicolescu A, Deleanu C, Oancea F. Antioxidant, cytotoxic and antimicrobial activity of chitosan preparations extracted from Ganoderma lucidum mushroom. Chem Biodiv. 2020;17:e2000175.

23. Sugahara S, Ueda Y, Fukuhara K, Kamamuta Y, Matsuda Y, Murata T, Kuroda Y, Kabata K, Ono M, Igoshi K, Yasuda S. Antioxidant effects of herbal tea leaves from Tacon (Smallanthus sonchifolius) on multiple free radical and reducing power assays, especially on different superoxide anion radical generation systems. J Food Sci. 2015;80:C2420-9.

24. Yang Y, Liu D, Wu J, Chen Y, Wang S. In vitro antioxidant activities of sulfated polysaccharide fractions extracted from Corallina officinalis. Int J Biol Macromol. 2011;49:1031-7.

25. Santos JS, Brizola VRA, Granato D. High-throughput assay and standardization for metal chelating capacity screening: a proposal and application. Food Chem. 2017;214:515-22.

26. Mathew M, Subramanian S. In vitro screening for anti-cholinesterase and antioxidant activity of methanolic extracts of ayurvedic medicinal plants used for cognitive disorders. Plos One. 2014;9:e86804.

27. Baydar H, Sangun MK, Erbas S, Kara N. Comparison of aroma compounds in distilled and extracted products of sage (Salvia officinalis L.). J Essent Oil Bear Plants. 2013;16:39-44. 
28. Ovidi E, Laghezza Masci V, Zambelli M, Tiezzi A, Vitalini S, Garzoli S. Laurus nobilis, Salvia sclarea and Salvia officinalis essential oils and hydrolates: evaluation of liquid and vapor phase chemical composition and biological activities. Plants. 2021;10:707.

29. Sharma Y, Velamuri R, Fagan J, Schaefer J, Streicher C, Stimson J. Identification and characterization of polyphenols and volatile terpenoid compounds in different extracts of garden sage (Salvia officinalis L.). Pharmacogn Res. 2020;12:149.

30. Tomi K, Kitao M, Konishi N, Murakami H, Matsumura Y, Hayashi T. Enantioselective GC-MS analysis of volatile components from rosemary (Rosmarinus officinalis L.) essential oils and hydrosols. Biosci Biotechnol Biochem. 2016;80:840-7.

31. Garzoli S, Laghezza Masci V, Franceschi S, Tiezzi A, Giacomello P, Ovidi E. Headspace/GC-MS analysis and investigation of antibacterial, antioxidant and cytotoxic activity of essential oils and hydrolates from Rosmarinus officinalis L. and Lavandula angustifolia Miller. Foods. 2021;10:1768.

32. Hay YO, Abril-Sierra MA, Sequeda-Castaneda LG, Bonnafous C, Raynaud C. Evaluation of combinations of essential oils and essential oils with hydrosols on antimicrobial and antioxidant activities. J Pharm Pharmacogn Res. 2018;6:216-30.

33. Jeon DH, Moon JY, Hyun HB, Cho KS. Composition analysis and antioxidant activities of the essential oil and the hydrosol extracted from Rosmarinus officinalis L. and Lavandula angustifolia Mill. produced in Jeju. J Appl Biol Chem. 2013;56:141-46.

34. Smigielski KB, Prusinowska R, Krosowiak K, Sikora M. Comparison of qualitative and quantitative chemical composition of hydrolate and essential oils of lavender (Lavandula angustifolia). J Essent Oil Res. 2013;25:291-9.

35. Kunicka-Styczynska A, Smigielski K, Prusinowska R, Rajkowska K, Kusmider B, Sikora M. Preservative activity of lavender hydrosols in moisturizing body gels. Lett Appl Microbiol. 2015;60:27-32.

36. Silha D, Svarcova K, Bajer T, Kralovec K, Tesarova E, Mouckova K, Bajerova P. Chemical composition of natural hydrolates and their antimicrobial activity on Arcobacter-like cells in comparison with other microorganisms. Molecules. 2020;25:5654.

37. Beale DJ, Morrison PD, Karpe AV, Dunn MS. Chemometric analysis of lavender essential oils using targeted and untargeted GC-MS acquired data for the rapid identification and characterization of oil quality. Molecules. 2017;22:1339.

38. Roby MHH, Sarhan MA, Selim KAH, Khalel KI. Evaluation of antioxidant activity, total phenols and phenolic compounds in thyme (Thymus vulgaris L.), sage (Salvia officinalis L.), and marjoram (Origanum majorana L.) extracts. Ind Crops Prod. 2013;43:827-31.

39. Dent M, Kovacevic DB, Bosiljkov T, Dragovic-Uzelac V. Polyphenolic composition and antioxidant capacity of indigenous wild dalmatian sage (Salvia officinalis L.). Croat Chem Acta. 2017;90:451-9.

40. Zeroual A, Sakar EH, Mahjoubi F, Chaouch M, Chaqroune A, Taleb M. Effects of extraction technique and solvent on phytochemicals, antioxidant and antimicrobial activities of cultivated and wild 
rosemary (Rosmarinus officinalis L.) from Taounate region (Northern Morocco). Biointerface Res Appl Chem. 2022;12:8441-52.

41. Adaszynska-Skwirzynska M, Dzieciol M. Comparison of phenolic acids and flavonoids contents in various cultivars and parts of common lavender (Lavandula angustifolia) derived from Poland. Nat Prod Res. 2017;31:2575-80.

42. Jakubczyk K, Tuchowska A, Janda-Milczarek K. Plant hydrolates-antioxidant properties, chemical composition and potential applications. Biomed Pharmacother. 2021;142:112033.

43. Bhattacharyya A, Chattopadhyay R, Mitra S, Crowe SE. Oxidative stress: an essential factor in the pathogenesis of gastrointestinal mucosal disease. Physiol Rev. 2014;94:329-54.

44. Francik S, Francik R, Sadowska U, Bystrowska B, Zawislak A, Knapczyk A, Nzeyimana A. Identification of phenolic compounds and determination of antioxidant activity in extracts and infusions of Salvia leaves. Materials. 2020;13:5811.

45. Sharopov FS, Wink M Setzer WN. Radical scavenging and antioxidant activities of essential oil components-an experimental and computational investigation. Nat Prod Commun. 2015;10:153-6.

46. Picciotto MR, Higley MJ, Mineur YS. Acetylcholine as a neuromodulator: cholinergic signaling shapes nervous system function and behavior. Neuron. 2012;76:116-29.

47. Kostyukovsky M, Rafaeli A, Gileadi C, Demchenko N, Shaaya E. Activation of octopaminergic receptors by essential oil constituents isolated from aromatic plants: possible mode of action against insect pests. Pest Manag Sci. 2002;58:1101-6.

48. Isman MB. Botanical insecticides, deterrents, and repellents in modern agriculture and an increasingly regulated world. Ann Rev Entomol. 2006;51:45-66.

49. Orhan I, Aslan S, Kartal M, Sener B, Baser KHC. Inhibitory effect of Turkish Rosmarinus officinalis L. on acetylcholinesterase and butyrylcholinesterase enzymes. Food Chem. 2008;108:663-8.

50. Ferreira A, Proenca C, Serralheiro MLM, Araujo MEM. The in vitro screening for acetylcholinesterase inhibition and antioxidant activity of medicinal plants from Portugal. J Ethnopharmacol. 2006;108:31-7.

51. Abdelgaleil SAM, Mohamed MIE, Badawy, MEI, El-Arami SAA, Fumigant and contact toxicities of monoterpenes to Sitophilus oryzae (L.) and Tribolium castaneum (Herbst) and their inhibitory effects on acetylcholinesterase activity. J Chem Ecol. 2009;35:518-25.

52. Souto AL, Sylvestre M, Tolke ED, Tavares JF, Barbosa-Filho JM, Cebrian-Torrejon G. Plant-derived pesticides as an alternative to pest management and sustainable agricultural production: prospects, applications and challenges. Molecules. 2021;26:4835.

53. Kharraf SE, Faleiro ML, Abdellah F, El-Guendouz S, El Hadrami EM, Miguel MG. Simultaneous hydrodistillation-steam distillation of Rosmarinus officinalis, Lavandula angustifolia and Citrus aurantium from Morocco, major terpenes: impact on biological activities. Molecules. 2021;26:5452.

54. Cutillas AB, Carrasco A, Martinez-Gutierrez R, Tomas V, Tudela J. Salvia officinalis L. essential oils from Spain: determination of composition, antioxidant capacity, antienzymatic, and antimicrobial bioactivities. Chem Biodiv. 2017;14:e1700102. 
55. Tundis R, Leporini M, Bonesi M, Rovito S, Passalacqua NG. Salvia officinalis L. from Italy: a comparative chemical and biological study of its essential oil in the Mediterranean context. Molecules. 2020;25:5826.

56. Silva MRM da, Ricci-Junior E. An approach to natural insect repellent formulations: from basic research to technological development. Acta Trop. 2020;212:105419.

57. Szwajgier D. Anticholinesterase activity of selected phenolic acids and flavonoids-interaction testing in model solutions. Ann Agric Environ Med. 2015;22:690-4.

58. Gulcin I, Scozzafava A, Supuran CT, Koksal Z, Turkan F, Cetinkaya S, Bingol Z, Huyut Z, Alwasel SH. Rosmarinic acid inhibits some metabolic enzymes including glutathione S-transferase, lactoperoxidase, acetylcholinesterase, butyrylcholinesterase and carbonic anhydrase isoenzymes. J Enzyme Inhib Med Chem. 2016;31:1698-702.

59. Vladimir-Knezevic S, Blazekovic B, Kindl M, Vladic J, Lower-Nedza AD, Brantner AH. Acetylcholinesterase inhibitory, antioxidant and phytochemical properties of selected medicinal plants of the Lamiaceae family. Molecules. 2014;19:767-82.

60. Khan H, Amin S, Kamal MA, Patel S. Flavonoids as acetylcholinesterase inhibitors: current therapeutic standing and future prospects. Biomed Pharmacother. 2018;101:860-70.

\section{Figures}



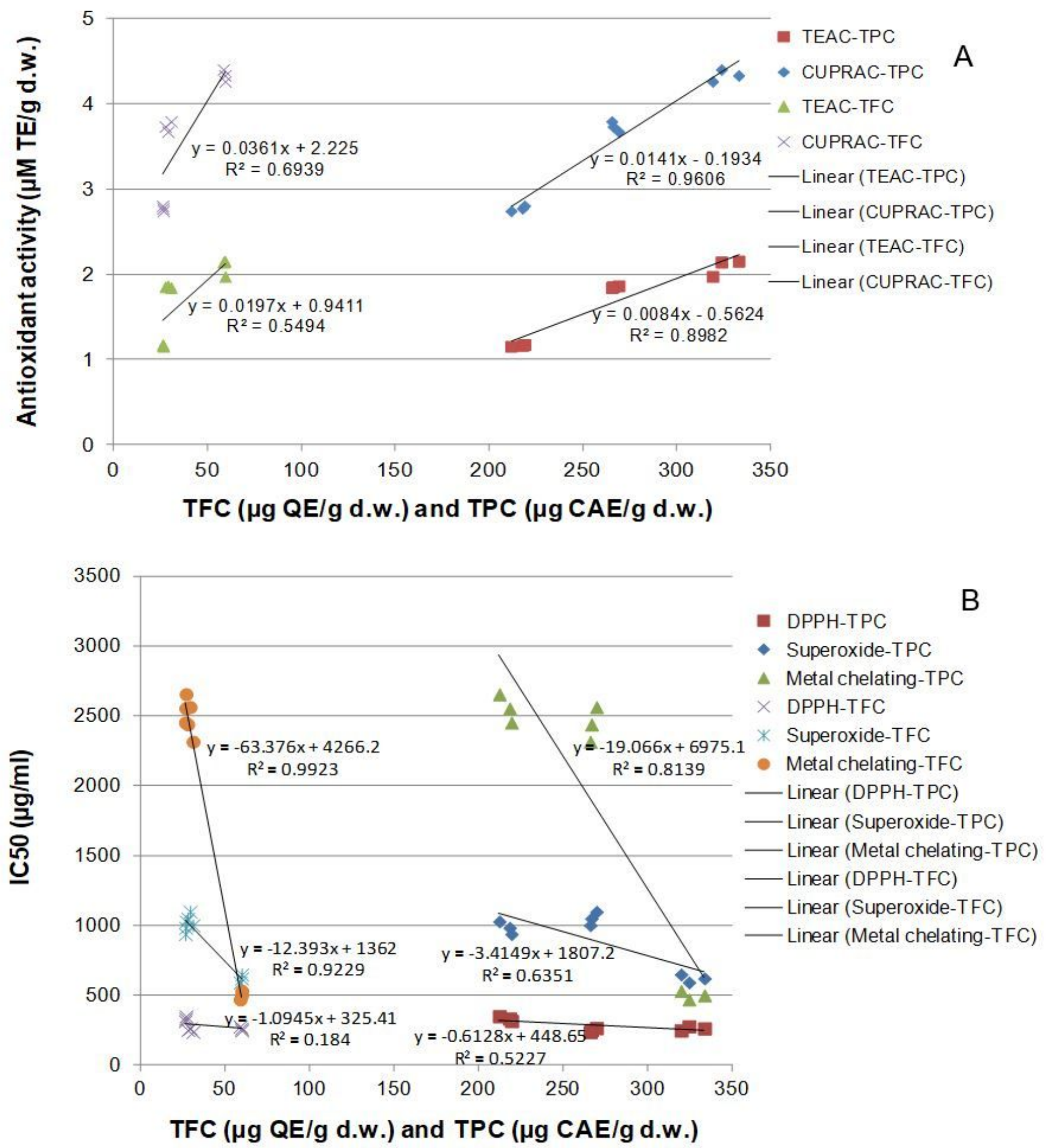

\section{Figure 1}

The correlation degree between total phenolic (TPC) and flavonoid content (TFC) of sage, rosemary and lavender hydrosols vs. TEAC and CUPRAC (A) and IC50 values determined by DPPH, superoxide and metal chelating assays (B). 

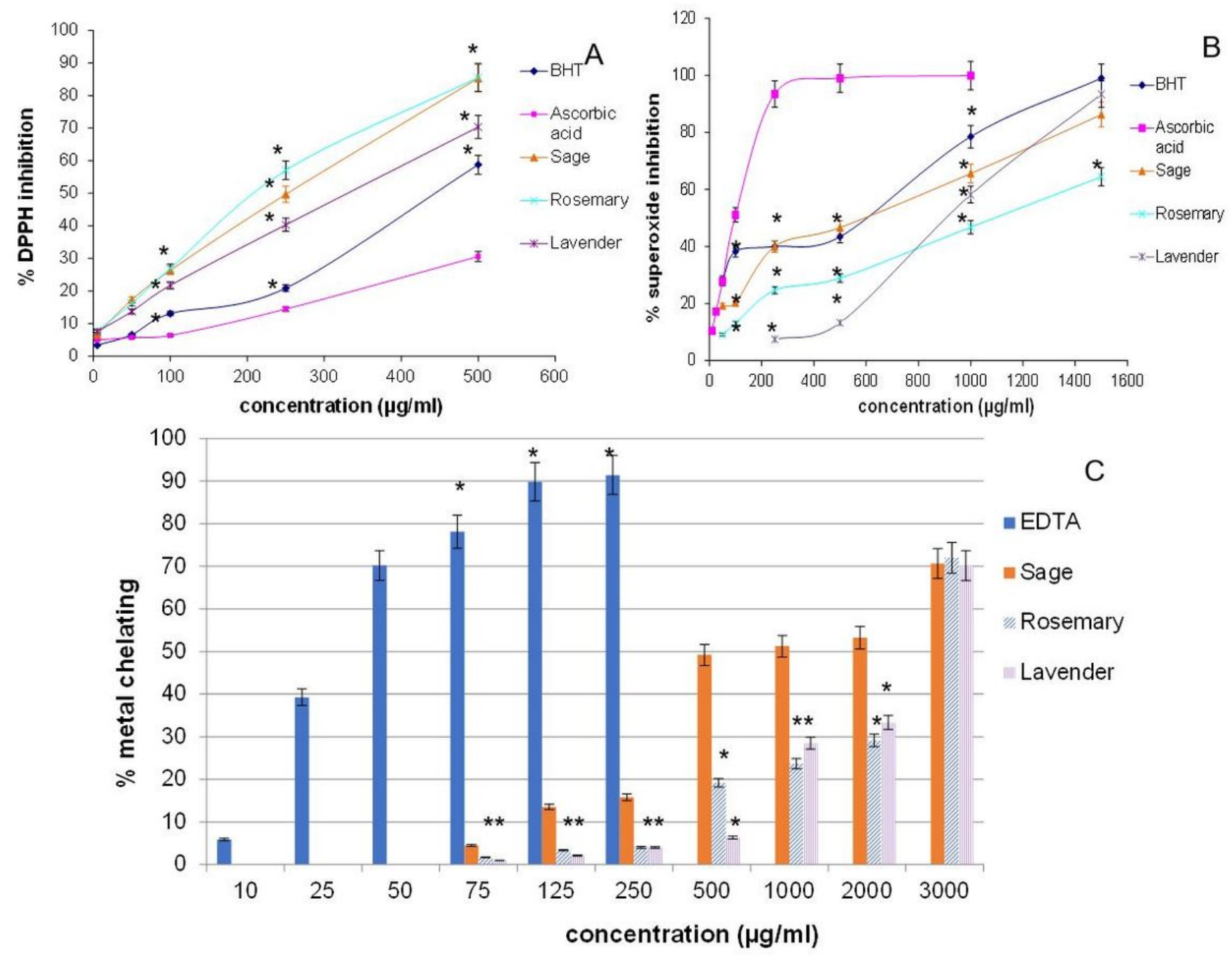

Figure 2

Inhibition capacity of sage, rosemary and lavender hydrosols towards free DPPH radicals (A), superoxide anion (B) and metal chelating activity (C). ${ }^{*} p<0.05$, compared to ascorbic acid (A, B). ${ }^{\star} p<0.05$, compared to sage hydrosol (C). 

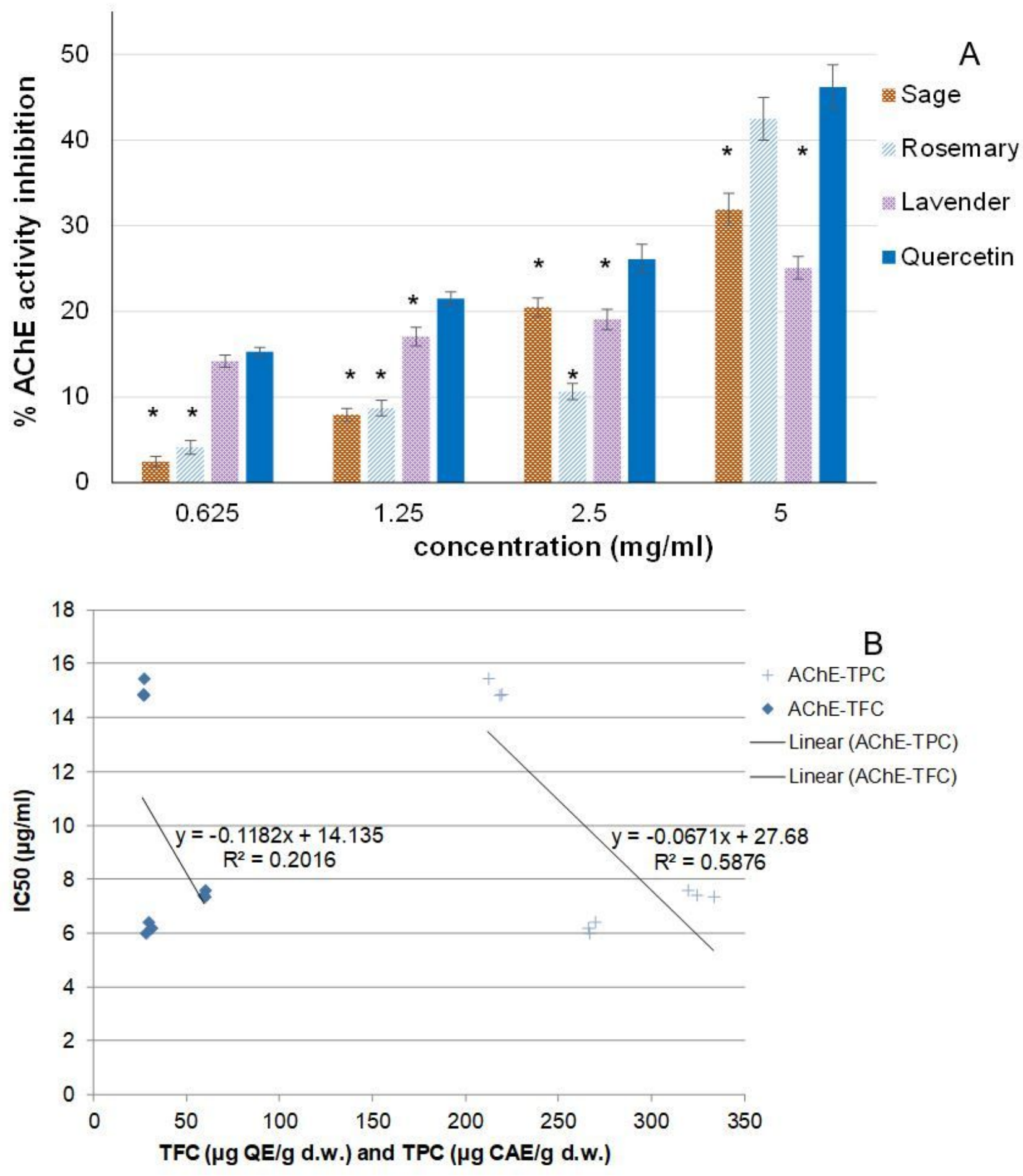

Figure 3

In vitro capacity of acetylcholinesterase inhibition determined for sage, rosemary and lavender hydrosols (A) and the correlation degree between IC50 values vs. total phenolic (TPC) and flavonoid content (TFC) of hydrosols (B). ${ }^{*} p<0.05$, compared to quercetin solution. 